\title{
Endogenous amyloidogenesis in long-term rat hippocampal cell cultures
}

\author{
Sarah J Bertrand", Marina V Aksenova, Micheal Y Aksenov, Charles F Mactutus and Rosemarie M Booze
}

\begin{abstract}
Background: Long-term primary neuronal cultures are a useful tool for the investigation of biochemical processes associated with neuronal senescence. Improvements in available technology make it possible to observe maturation of neural cells isolated from different regions of the rodent brain over a prolonged period in vitro. Existing experimental evidence suggests that cellular aging occurs in mature, long-term, primary neuronal cell cultures. However, detailed studies of neuronal development in vitro are needed to demonstrate the validity of long-term cell culture-based models for investigation of the biochemical mechanisms of in vitro neuronal development and senescence.

Results: In the current study, neuron-enriched hippocampal cell cultures were used to analyze the differentiation and degeneration of hippocampal neurons over a two month time period. The expression of different neuronal and astroglial biomarkers was used to determine the cytochemical characteristics of hippocampal cells in long-term cultures of varying ages. It was observed that the expression of the intermediate filament nestin was absent from cultures older than 21 days in vitro (DIV), and the expression of neuronal or astrocytic markers appeared to replace nestin. Additionally, morphological evaluations of neuronal integrity and Hoescht staining were used to assess the cellular conditions in the process of hippocampal culture development and aging. It was found that there was an increase in endogenous production of $A \beta_{1-42}$ and an increase in the accumulation of Congo Red-binding amyloidal aggregates associated with the aging of neurons in primary culture. In vitro changes in the morphology of coexisting astrocytes and cell culture age-dependent degeneration of neurodendritic network resemble features of in vivo brain aging at the cellular level.
\end{abstract}

Conclusion: In conclusion, this study suggests that long-term primary CNS culture is a viable model for the study of basic mechanisms and effective methods to decelerate the process of neuronal senescence.

Keywords: Cell Culture Amyloid Peptide, Neurodegeneration/Aging

\section{Background}

As a result of the advances in isolation and culturing of fetal and adult central nervous system (CNS) cells achieved during the last two decades [1,2], primary neuronal cell culture has become a powerful tool for isolating cellular and molecular mechanisms of neuronal development and death $[1,3,4]$. Despite the routine success at long-term culturing of primary rodent neurons [5-9], the application of this potentially very useful approach for modeling of neuronal cell aging remains limited. The standard protocols that allow prolonged

\footnotetext{
* Correspondence: bertrans@email.sc.edu

University of South Carolina, Program in Behavioral Neuroscience, Department of Psychology, Columbia, SC 29208, USA
}

CNS cell culturing (including culturing of hippocampal neurons) are now widely available $[10,2]$, however, systematic studies of the differentiation state, cytochemical, and morphological characteristics of brain cells remaining viable over long term in vitro are needed.

Although in vivo animal models can be used to reveal many important aspects of neuronal development, dysfunction, and degeneration, the inherent complexity of nervous tissue often obscures the overall understanding of molecular, biochemical, and structural observations. The in vitro system lacks an intact tissue environment; nevertheless, the presence of a homogenous cell population allows us to identify specific mechanisms underlying the chemical and morphological changes seen in vivo [6]. Using long term primary cell culture to
C Biomed Central

() 2011 Bertrand et al; licensee BioMed Central Ltd. This is an Open Access article distributed under the terms of the Creative Commons Attribution License (http://creativecommons.org/licenses/by/2.0), which permits unrestricted use, distribution, and reproduction in any medium, provided the original work is properly cited. 
decipher the underlying development of the cells of the hippocampus allows examination of where the initial dysfunction takes place that leads to some of the symptoms of neurodegeneration. Understanding what a mature neuron looks like, and when it matures in culture, will help facilitate the development of more efficient in vitro testing.

In the current study we used the lack of nestin immunoreactivity, as well as various morphological categorizations, to classify our cultures as mature. Nestin is a type VI neurofilament expressed in the developing CNS, specifically in progenitor cells undergoing differentiation [11-13]. Specific mature neuronal and astrocytic markers, MAP-2 and GFAP, have been found to be coexpressed with nestin in early, primary, neuronal cell cultures $[14,11]$. The co-localization of these markers and nestin indicate the event of differentiation. Conversely, there should be little to no expression of the intermediate fiber marker nestin in mature primary neuronal cultures [14].

Increased amyloid-beta peptide $(A \beta)$ formation is a common accompaniment of brain aging [15-17]. Accumulation of abnormal protein aggregates, including the misfolded $A \beta$ protein, is the manifestation of progressively deteriorating capacity of aging biological systems to withstand extrinsic and intrinsic hazards [18-20]. Our current study was designed to investigate the possibility of endogenous amyloid beta peptide formation and accumulation of misfolded protein aggregates in hippocampal neurons during their development and maturation in vitro.

$\mathrm{A} \beta$ peptides arise from the cleavage of amyloid precursor protein (APP) [21]. $\beta$-and $\gamma$-secretases cleave the unprocessed APP in succession, resulting in the formation of $A \beta$ peptide $[15,22,16,23]$. Numerous studies have used rodent primary hippocampal cell cultures as an experimental model of normal biogenesis of $A \beta[24,13]$. Rat hippocampal cells in primary cultures express $\mathrm{APP}_{770}, \mathrm{APP}_{751}$, and $\mathrm{APP}_{695}[24,25]$ and the amyloidogenic route of APP processing resulting in the endogenous $A \beta_{1-40}$ or $A \beta_{1-42}$ generation may naturally occur in primary neuronal cultures [26].

The A $\beta$ monomers released from cells transform into $\beta$-pleated sheet aggregates to initiate the process of neuronal degeneration associated with the decline in metabolic activity and oxidative damage of cultured hippocampal neurons $[27,28]$. It was reported that the rodent $A \beta$ is less likely to form large fibrillary structures due to three amino acid substitutions compared to the human sequence. Nevertheless, neurotoxic and pro-oxidant properties of the rat variety of $A \beta$ 1-42 have proven to be the same as human [29]. Most amyloid peptides interact strongly with cell membranes and this interaction is enhanced by conditions which favor $\beta$ - sheet formation. The excessive release of $A \beta$ from cultured rat hippocampal neurons can result in the increase of amyloid-binding dye fluorescence in the culture medium and $A \beta$-mediated toxicity [30].

Although increased $A \beta$ formation and the production of aggregates have been observed accompanying the process of neuronal aging $[17,18]$, low levels of $A \beta$ derived from the natural processing of APP isoforms have been found both in vivo and in vitro [17,22]. Normal physiologic levels of $A \beta$ are thought to be important in regulating neurotransmission $[15,16,23,24]$, consequently many researchers suggest that $A \beta$ should only be regarded as toxic when the production and degradation are imbalanced $[15,16]$.

Overall, the purpose of this study is to investigate the usefulness of long term primary hippocampal cell culture for understanding the link between endogenous $A \beta$ production, differentiation and maturation in vitro. In order to discern this link we aim to identify criteria by which a culture can be classified as mature. These classifications can help us properly assess the endogenous levels of $A \beta$ and the accumulation of misfolded $A \beta$ proteins into aggregates as physiological, and not pathological, processes of aging. The ability to classify the maturity of neurons will also strengthen the cell culture model as a whole, giving researchers the ability to more definitively speak about influences on the aging nervous system.

\section{Results}

\section{The long-term hippocampal cell culture maturation and} aging

Primary embryonic hippocampal culture preparations used in this study are classified as moderate-high density (160-180 cells $\left./ \mathrm{mm}^{2}\right)$. Soon after the adherence to the surface of the cell culture plate, viable hippocampal cells began expressing marker proteins that indicate their commitment to either the neuronal or astrocytic differentiation. The representative DIC microscopy images in figure $1 \mathrm{~A}$ illustrate that the cells were initially small with no, or a very small number of, neuritic outgrowths at 4 DIV, and later form a visible network by 14 DIV. Extensive networking of neurites and the defined appearance of pyramidal cells at DIV 21-35, indicated this was a stage of maturity for the cell culture. Aging hippocampal cells (DIV 40-65) appeared to have progressively less defined connections with excessive bundling of neurites and larger, more defined cell bodies.

Consistent with the DIC imaging of developing neural networks were images of Nestin/MAP-2 immunofluorescence from the long-term hippocampal cultures of different ages (Figure 1B). In 7-14 DIV hippocampal cells nestin immunoreactivity was generally localized within the axonal growth cones. Neuronal maturation associated with extensive dendritic arborization was 


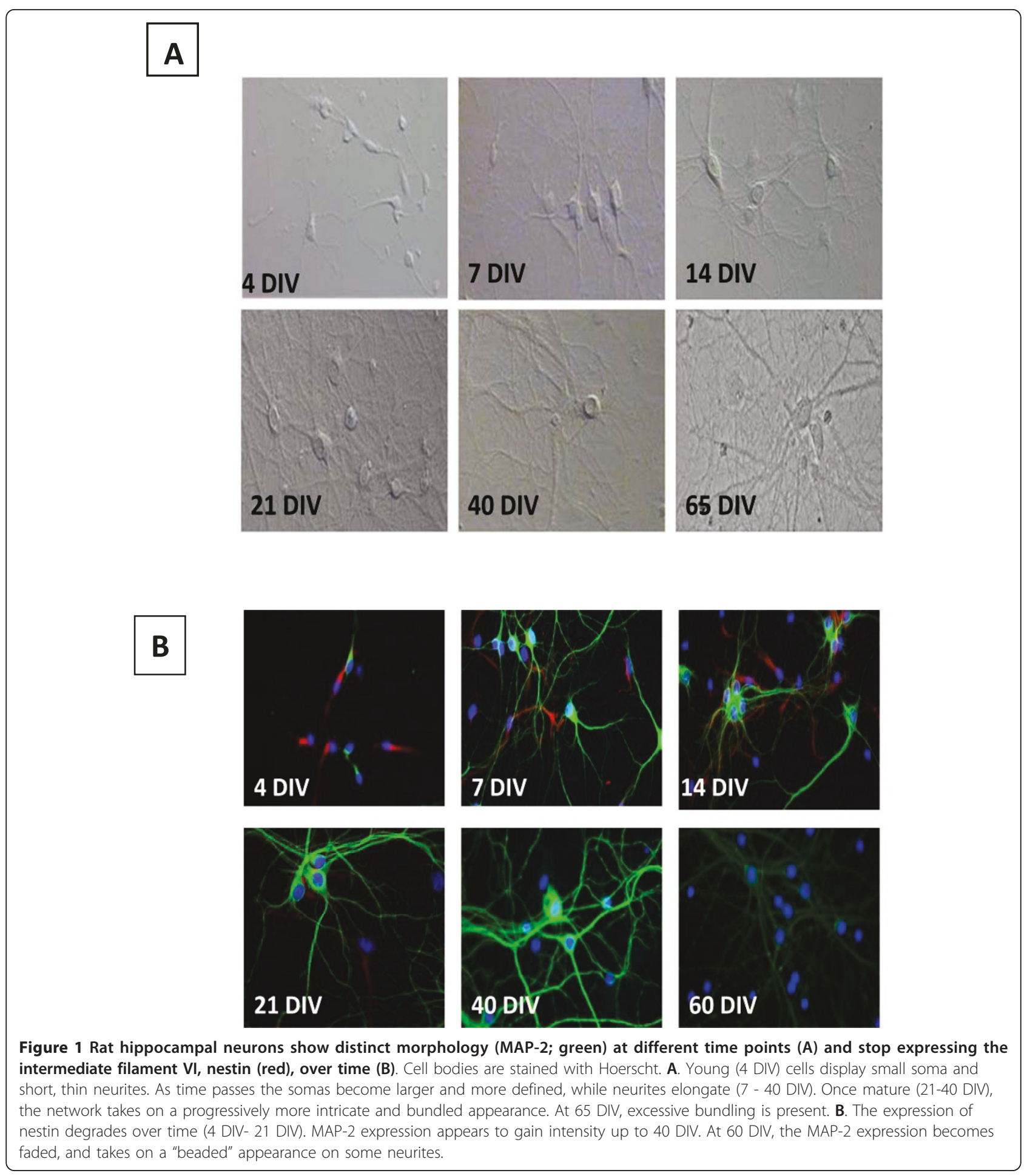

characterized by a gradual decline of the expression of this immature neurofilament protein and the increase of MAP-2 expression. As shown in figure 1B, after 14 DIV the majority of the neuronal population in the longterm hippocampal cell culture became predominantly MAP-2 expressing principle pyramidal neurons.
Nevertheless, nestin immunoreactivity could be detected in some cells until DIV 21. Hippocampal neuronal cells expressing nestin along with MAP-2 were typically found in cell clusters at this age (21 DIV).

Observations of the mature hippocampal primary cultures during their long-term maintenance clearly 
showed that the stationary phase, during which cultured cells showed no noticeable changes in morphology, may continue until DIV 40. Signs of neuritic network deterioration began to occur after $40 \mathrm{DIV}$. Immunoreactivity of MAP-2 in these aged hippocampal cell cultures also revealed varicosities along the processes, giving them a 'beaded' appearance, as shown in figure 1B at 60 DIV.

Primary rat fetal hippocampal cultures were neuronenriched throughout long-term maintenance. The fully mature hippocampal cell culture (21-35DIV) contained $15 \pm 5 \%$ GFAP positive cells. The number of astrocytes remained stable throughout the cell culture aging period and did not exceed $20 \%$ even in very old (65 DIV) cultures (data not shown). However, the astrocytic cell morphology and GFAP expression changed with the aging of the cell culture age (Figure 2). In long-term hippocampal cultures of 45-60 DIV, astrocytes exhibited very intensive GFAP immunostaining and displayed an extensively branched network of processes (Figure 2B). GFAP expressing cells had thicker processes relative to MAP-2 expressing cells, and their nuclei appeared to be flat and more oblong than MAP-2 expressing cells.

Results of immunoblotting analyses of neuronal (MAP-2, NSE) and astrocytic (GFAP, GS) marker proteins in hippocampal cell lysates (Figure 3A, B) were consistent with the results of the immunofluorescent microscopy and neuronal/astrocytic cell counting. The MAP-2/GFAP immunoreactivity ratio significantly ( $\mathrm{P}=$ $0.002<0.05)$ decreased from $2.70 \pm 0.22$ to $1.50 \pm 0.08$ between 14 and 25 DIV when hippocampal cell cultures reached the peak of their development. No significant changes in the MAP-2/GFAP ratio have been found in fully mature hippocampal cultures between $25 \mathrm{DIV}$ and $35 \operatorname{DIV}(1.50 \pm 0.08$ and $1.34 \pm 0.07 ; \mathrm{P}=0.191>0.05)$. The end of the stationary phase (35 DIV) was marked by the significant decrease of the MAP-2/GFAP ratio at $45 \operatorname{DIV}(0.64 \pm 0.03 ; \mathrm{P}=0.0001<0.05)$, which was attributed to the sharp drop in MAP-2 immunoreactivity but not to the increase in GFAP immunoreactivity. The observed changes in levels of immunoreactive MAP-2 corresponded well with the results of anti-MAP2 immunofluorescent microscopy, revealing signs of neuronal dendritic network degeneration at this time point (40-50 DIV). Consistently, as shown by the images of the Western blots in Figure 3, the intensity of protein bands corresponding to synaptodendritic markers MAP2 and PSD 95 exhibited pronounced decreases between 35 DIV and 45 DIV compared to NSE, GS and $\beta$-actin.

\section{Amyloid beta -peptide release and deposition of $\beta$ - pleated sheet protein aggregates}

The presence of specific A $\beta$ 1-42 immunofluorescence in cultured hippocampal neurons indicates the possibility of endogenous $A \beta$ production. Only negligible levels of extracellular A $\beta$ 1-42 immunoreactivity were detected by direct ELISA in the cell culture medium at DIV 7 and DIV 14 (Figure 4A). The progressive accumulation of $A \beta 1-42$ in the growth medium was starting in the stationary phase of cell culture development (21-35 DIV) and peaked at 120-150 nM during the period of in vitro aging between 40 DIV and 60 DIV (Figure 4A).

In this study, the long-term maintenance of hippocampal cell cultures continued until 65 DIV. Live-dead staining was routinely performed to determine cell viability. Double labeling with calcein AM and Congo Red revealed the presence of cells with membrane integrity and the capability to retain the fluorescent product of the calcein AM hydrolysis fairly long into culturing (65 DIV; Figure 4D).

Results of the Congo Red staining of long-term hippocampal cultures at different stages of their development are shown in Figure 4B. Congo Red staining of cell bodies or processes was rarely observed in hippocampal cell cultures until 21 DIV. However, after 35 DIV the Congo Red stained amyloid-like depositions were frequently found in association with the dendritic network and in the cell body (Figure 4C). In cultures older than 40 days, increasing numbers of cells with Congo Redpositive somata were observed (Figure 4E). Total number of cells containing Congo-red positive amyloidal aggregates was much higher in older cells (60 DIV; Figure 4E). Co-labeling with calcein AM and Congo red detected many calcein AM-positive cells some with the presence of Congo Red, as shown by the yellow arrows in Figure 4D.

\section{Discussion}

The technology of CNS cell culturing continues to evolve, bringing forward novel perspectives to advance the understanding of basic principles of neural functioning by using isolated neural cells in a controlled environment. In this study we used the techniques for culturing rat fetal hippocampal neurons developed by Brewer and co-authors [1-3,7,31]. When this method is used, isolated neurons remain viable for long periods of time without the need for astroglial feeder co-cultures [10]. Our own experience [5] and reports from other investigators $[7,8,6,32]$, have documented the successful maintenance of viable cultures containing primary rodent fetal neurons for 60-70 days or longer. The ability to maintain cell cultures for extended periods of time allows further understanding of the fundamental processes of development and aging within the neuronal populations.

Despite the abundance of published studies carried out in primary CNS cultures, important aspects of neuronal differentiation in vitro remain ambiguous. The data reported here describe the long-term time course 

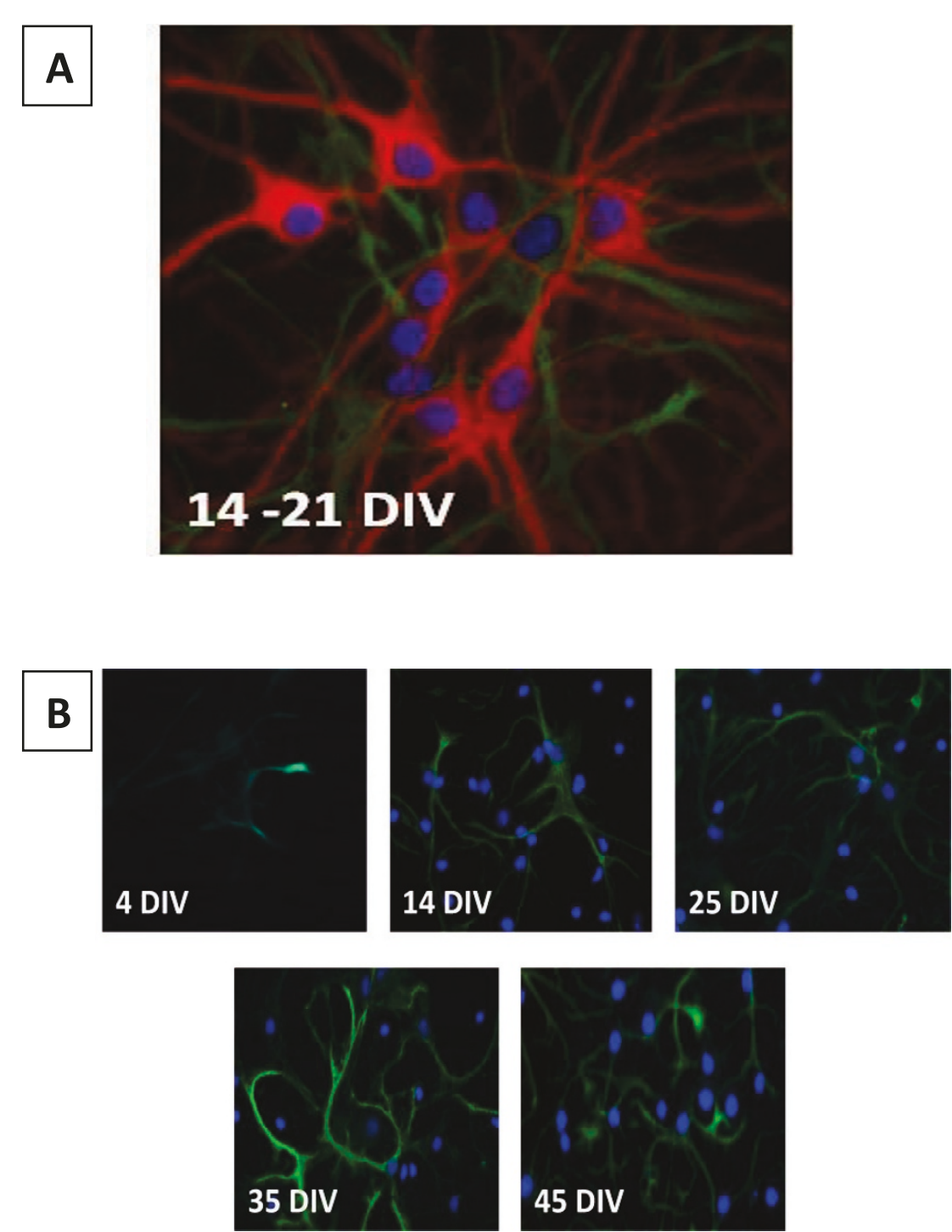

Figure 2 Astrocytic growth consists of arborization rather than division. A. A representative image of MAP (red) and GFAP (green) expression. Cell nuclei are stained with Hoerscht (blue). Although there are multiple cell bodies present, only one is shown to be expressing GFAP. B. At earlier time points, GFAP expression is limited due to the culture medium which does not support astrocytic growth. Although there appears to be an increase in GFAP expression as cultures age, cell bodies associated with GFAP expression remain at similar levels, but there is an increase in arborization.

of maturation of isolated primary rat hippocampal cells in culture. We report that at 21 DIV, isolated hippocampal neurons completely switch from the expression of the intermediate type VI neurofilaments (nestin) to the synthesis of more advanced neurofilaments containing MAP-2. These data suggest that hippocampal cultures younger than 21 DIV do not resemble fully mature neurons as seen in vivo $[11,6]$.

This culturing protocol uses a medium specifically formulated to promote neuronal survival and does not support glial proliferation [1]. However, it does not prevent the development of viable progenitor cells from differentiating into astrocytes during the development of the cell culture. Astrocytic development is sometimes viewed as a necessary event for the long-term survival of neuronal cells in culture $[6,14]$. We found that the prevalence of the neuronal phenotype (MAP-2 expressing cells) is maintained through all stages of the cell culture development. Cell populations in fully mature, longterm hippocampal cell cultures could include up to $20 \%$ GFAP-positive cells and relative numbers of astrocytes did not show further increase during the cell culture aging period. The gradual increase in GFAP expression and enrichment of the network of GFAP-positive cell 


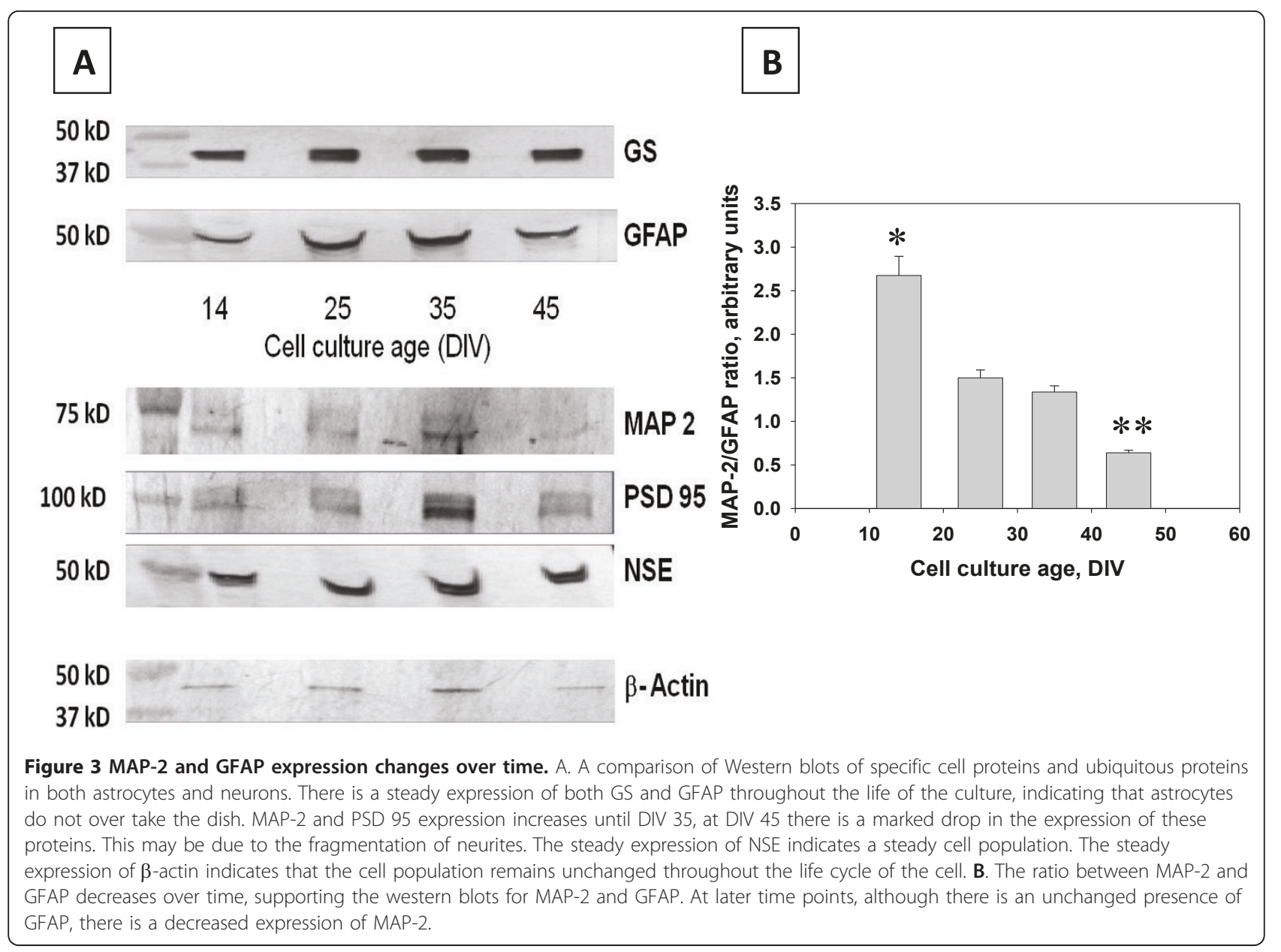

processes, may be explained by slow (in comparison to neurons) maturation of existing astrocytes in B27-supplemented Neurobasal medium, which is not optimized to support astrocytic growth [6,1]. Alternatively, the enhanced arborization and GFAP expression may be attributable to astrocytic activation adjunct to the cell culture aging $[33,5,13]$. As in vivo, primary long-term cell culture aging is associated with the progressive oxidative damage of hippocampal neurons [5] and astrocytes are known to respond to various physiological or noxious stimuli including oxidative stress with increased expression of GFAP [14]. However, the results of our current study show signs of progressive degeneration of both MAP-2 and GFAP-containing networks during the later stages in the long-term hippocampal cell cultures.

Our study adds to the literature that investigates the endogenous release of $A \beta[34,17,16,15,22,26]$ and potential deposition of amyloid-like aggregates in the process of development and aging of isolated hippocampal cells [17]. Consistently, we have detected the expression of APP and the presence of intracellular A $\beta$ 1-42 immunoreactivity in long-term hippocampal cultures. The longitudinal monitoring of extracellular $A \beta$ 1-42 immunoreactivity in primary hippocampal cell culture from DIV 4 until DIV 60 has shown that young, actively differentiating hippocampal cells have very low levels of physiological secretion of amyloidogenic $A \beta$. Direct $A \beta$ ELISA measurements for 7-15DIV cell cultures that we report are consistent with similar data, which can be found in recent publications [26]. Notably, our experiments show that the increase of extracellular $A \beta$ coincided with the complete maturation of synaptodendritic networks in hippocampal cultures, which indicates a potential relationship between increasing neuronal activity and the secretion of $A \beta$. Indeed, several recent studies $[15,22,23,34]$ suggested that the formation of $A \beta$ monomers play a role in the regulation of synaptic transmission.

Amyloid-like protein aggregates are thought to disrupt normal neuronal functioning by irreversible spontaneous insertion into cell membranes. The existing evidence suggests that the misfolded and aggregated proteins are essential elements in the vast majority of age-related neurodegenerative diseases [19]. Therefore, we used the 


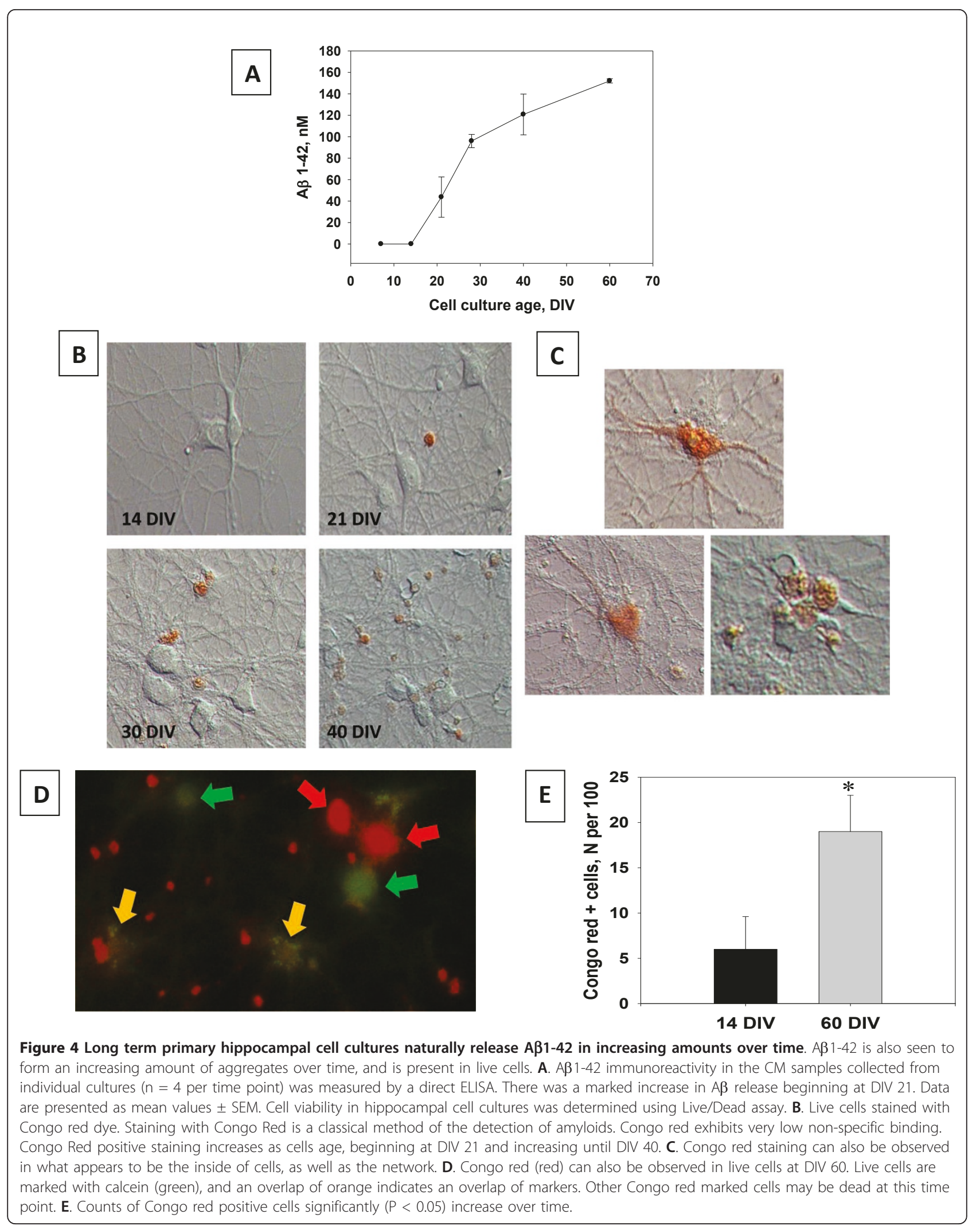


Congo Red staining to determine whether the changes in extracellular levels of $A \beta$ 1-42 were associated with the deposition of $\beta$-amyloids in long-term hippocampal cell cultures. The presence of Congo Red-positive aggregates associated with the network of processes and cell bodies of hippocampal cells appeared to mark the beginning of the period of decay in the long-term cell culture. Congo Red stained aggregates were consistently observed in long-term cultures after 30 DIV when the levels of extracellular $A \beta$ 1-42 grew higher than 100 nM. The appearance of cell-associated amyloid-like aggregates became more frequent as the cell cultures continued to age and correlated well with morphological signs of deterioration of dendritic networks. Intriguingly, the cell culture ages when the presence of $\beta$-amyloidal aggregates were observed in the current study corresponded well with previously reported time course of protein oxidative damage in aging long-term hippocampal cell cultures $[5,35,36]$.

The A $\beta$ release and the following changes of the specific $\beta$-amyloid labeling preceded the decline of cell densities in aging hippocampal cultures. The pronounced increase in the number of cells exhibiting positive Congo Red staining of the somata in 60 DIV long-term cultures could be explained by the increased membrane permeability of decaying hippocampal cells which allowed Congo Red access to the intracellular compartment. Nevertheless, the overlap between the calcein AM and the Congo Red positive labeling indicated that, even in very old cultures, amyloid like aggregates could be found in the remaining alive hippocampal cells, which continue to maintain intact membrane integrity. On the other hand, the appearance of Congo Red fluorescence in dead (calcein AM-negative) cells is consistent with the suggestion that the presence of $\beta$-sheet structured protein aggregates may be a marker of neural cell injury and decay $[37,38]$.

Studies of primary neuronal cultures beyond DIV 30 are infrequent $[6,5,1]$. Moreover, studies characterizing the development and senescence of neuronal cells in vitro without any treatment are difficult to identify in the literature. The current study not only joins the limited literature of long term cultures past DIV 30, we also characterized some important developmental milestones of note when using primary cell cultures. We found that neurons in primary culture undergo distinct developmental phases: differentiation, maturation, steady state, and senescence. Viability of these cell cultures was verified using immunoblotting of important structural proteins, immunoreactivity of important neuronal and glial markers, and differential interference contrast images to track visible damage on the cells.

Differentiation (DIV4-14) was characterized by the presence of nestin immunoreactivty and the prevalence of small cells with short processes and little to no branching in DIC images. Maturation (DIV 14-21) was classified as a time when the majority of nestin expressing cells began expressing MAP-2 (or GFAP), and a more defined network of neurites and larger, more defined cell bodies were present in DIC images. The steady state (DIV 21-35) was defined as the point in time when the neuronal cells in culture no longer displayed any noticeable changes. Senescence (DIV40-60) was defined as a decrease in total cell number, the presence of "beading" of the processes, a steady rise in $A \beta$ production and an increase in aggregate formation.

\section{Conclusions}

The phenomenon of cellular aging takes place in longterm primary neuronal cell cultures $[13,4,5]$. The present study found that endogenous cell senescence-associated amyloidogenesis in vitro occur in long-term hippocampal cell cultures. This outcome presents similar observations seen in the patterns of neuronal aging seen in animals, therefore, suggesting the possibility that long-term primary cell culture could serve as a model for particular aspects of aging, such as the study of neurodegenerative diseases. In sum, our results indicate that long-term primary cell cultures may be a useful instrument for designing and testing effective ways to delay neuronal senescence and other age related phenomenon.

\section{Methods}

Primary hippocampal cell cultures were prepared from 18-day-old Sprague-Dawley rat fetuses. Procedures were carried out in accordance with the University of South Carolinas Institutional Animal Care and Use Committee. Rat hippocampi were dissected and incubated for 10 min in a solution of $2 \mathrm{mg} / \mathrm{ml}$ trypsin in Hank's balanced salt solution (HBSS) buffered with $10 \mathrm{mM}$ HEPES (GIBCO Life Technologies, Paisley, Scotland). The tissue was then exposed for 2 min to soybean trypsin inhibitor $(1 \mathrm{mg} / \mathrm{ml}$ in HBSS) and rinsed 3 times in HBSS. Cells were dissociated by trituration and distributed to glass bottom $35 \mathrm{~mm}$ and 96-well poly-L-lysine-coated plastic culture dishes (Costar, Cambridge, MA). Dishes were coated with a poly-L-lysine 48 hours prior to culturing. Initial plating densities were about $160-180$ cells $/ \mathrm{mm}^{2}$. At the time of plating, plates contained DMEM/F12 (GIBCO) supplemented with $100 \mathrm{~mL} / \mathrm{L}$ fetal bovine serum (Sigma Chemicals, St. Louis, MO). After a 24-hr period, DMEM/F12 was replaced with an equal amount of Neurobasal medium supplemented with $2 \%$ v/v B-27, 2 mM GlutaMAX supplement and 0.5\% w/v D-(1) glucose (all ingredients are from GIBCO). Neurobasal, B27supplemented medium was used because it favors neuronal cell development and is not supportive for astrocytic proliferation. Cultures were maintained at $37^{\circ} \mathrm{C}$ in 
a 5\% CO2/95\% room air-humidified incubator at all times [5]. The long term maintenance of hippocampal cell cultures was carried out by replacing two thirds of the neurobasal medium with fresh medium after two weeks.

The morphology of hippocampal cells was examined at different time points $(4,7,14,21,40$, and 60 days in vitro (DIV) using differential interference contrast (DIC) microscopy as shown in Figure 1A. The fluorescent Hoescht staining of cell nuclei was used to monitor age-related changes in the cell density. The viability of hippocampal cells in long-term cultures was monitored by the fluorescent calcein AM/ethidium bromide cell labeling (Live/Dead cell viability kit, Invitrogen, Carlsbad, CA).

Immunofluorescent labeling with primary antibodies against nestin, MAP-2, and GFAP were used to assess the maturity of hippocampal neurons and detect cells with the neuronal astrocytic phenotype in long-term cultures of different ages (See Table 1 for antibodies used in this study). Nestin is a type VI intermediate filament protein transiently expressed by progenitor cells at the early stages of neurogenesis. Upon differentiation, nestin becomes down-regulated and replaced by neuron or astrocytic specific filaments, in this case MAP-2 and GFAP were used, respectively. Cells were fixed with an acetic acid/methanol solution for 5 minutes prior to blocking with a $10 \%$ horse serum solution. Secondary antibodies were Alexa Dye-conjugated host animal-specific IgG (Invitrogen). In all immunolabeling analyses the specificity of staining was confirmed by the exclusion of the subsequent primary antibody. The deposition of amyloid-like aggregates in the long-term hippocampal cell cultures was studied using the $\beta$-amyloid-binding Congo Red (Sigma Aldrich). Compared to other amyloid-binding dyes, such as thioflavin $\mathrm{H}$ or S, Congo Red exhibits very low non-specific binding and cannot be internalized by the cells, due to the presence of two hydrophilic sulfonic groups. Staining of non-fixed hippocampal cells with Congo Red and microscopic imaging of the results was carried out as previously described [39].

Total cell lysates prepared from hippocampal cells that had reached the ages of $14,25,35$, and 45 DIV as previously described [40] were analyzed by Western blotting and using primary antibodies against neuron- or astrocyte-specific cytoskeletal (MAP-2 and GFAP) and cytosolic (neuron- specific enolase, NSE and glutamine synthetase, GS) marker proteins. In parallel Western blots of the hippocampal cell lysates were immunostained with antibodies against synaptic (PSD 95) and ubiquitous cytoskeletal proteins ( $\beta$ actin).

Direct ELISA measurements of the $A \beta$ 1-42 immunoreactivity in cell-conditioned medium (CM) samples were performed using the rabbit polyclonal anti-A $\beta$ 1-42 antibody. Serial dilutions of freshly prepared stocks of the synthetic rat $A \beta$ 1-42 (0-2500 nM) (Anaspec, CA) with cell culture medium were used for calibration.

Immunofluorescent imaging was carried out under $20 \times$ magnification using the inverted fluorescent microscope (Nikon Eclipse TE2000-E) as previously described $[4,40]$. Immunofluorescent images, images of specific Congo Red binding, and DIC images were captured using a CCD camera. Merged images were produced and analyzed by the NIS Elements imaging software (Nikon). Hippocampal neurons (MAP-2 labeled cells) and astrocytes (GFAP labeled cells) were counted using the Object counting option of the NIS Elements imaging software package in 4 random fields of vision in cell cultures of different ages. For each field of vision total numbers of hippocampal cells were determined using the counting of Hoescht fluorescent stain of cell nuclei.

Statistical comparisons were made using ANOVA and planned comparisons were used to determine

Table 1 Antibodies Used

\begin{tabular}{lllll}
\hline Name & Method & Dilution & Animal Conjugate & Manufacturer \\
\hline MAP-2 & ICC/F; WB & $1: 500 ; 1: 1000$ & Rabbit Monoclonal & Santa Cruz \\
\hline GFAP & ICC/F;WB & $1: 5000$ & Chicken Monoclonal & Abcam \\
\hline Glutamine Synthase & WB & $1: 10000$ & Mouse Monoclonal & Chemicon \\
\hline Neuron Specific Enolase & WB & $1: 5000$ & Chicken Polyclonal & Aves \\
\hline PSD-95 & WB & Goat Polyclonal & Abcam \\
\hline$\beta$ Actin & WB & & Abcam \\
\hline A $\beta$ 1-42 & WB; ICC/IF & $1: 5000$ & Rabbit Polyclonal & Abcam \\
\hline Nestin & ICC/F & $1: 1000$ & Sigma \\
\hline Anti-Rabbit lgG & WB & $1: 1500$ & & Sigma \\
\hline Anti-Mouse IgG & WB & $1: 1500$ & & Abcam \\
\hline Anti-Goat IgG & WB & $1: 1500$ & Abcam
\end{tabular}


specific treatment effects. Significant differences were set at $P<0.05$.

\begin{abstract}
Abbreviations
AB: Amyloid Beta; GFAP: Glial fibrillary acidic protein; APP: Amyloid precursor protein; GS: Glutamine synthase; CNS: Central Nervous System; MAP-2: Microtubule associated protein 2; DIC: Days in vitro; NSE: Neuron specific enolase; DIV: Differntial interference contrast; PSD 95: Post-synaptic density 95
\end{abstract}

\section{Acknowledgements}

This work is supported by University of South Carolina Research Foundation grant, NIH Grant \# DA013137, and DA031604.

\section{Authors' contributions}

SJB assisted in carrying out immunohistochemistry, morphologically characterized cells, and drafted the manuscript. MVA carried out ELISA, and assisted in immunohistochemistry. MYA carried out Western Blot analysis, aided in manuscript preparation, and performed the statistical analysis. MVA and MYA conceived of the study, and participated in its design. CFM and RMB participated in the design and coordination of the experiments, as well as helping to draft the manuscript. All authors read and approved the final manuscript.

Received: 20 December 2010 Accepted: 10 May 2011

Published: 10 May 2011

\section{References}

1. Brewer GJ, Torricelli JR, Evege EK, Price PJ: Optimized survival of hippocampal neurons in B27-supplemented Neurobasal, a new serumfree medium combination. J Neurosci Res 1993, 35(5):567-76.

2. Brewer GJ, Torricelli JR: Isolation and culture of adult neurons and neurospheres. Nat Protoc 2007, 2(6):1490-8.

3. Brewer GJ: Regeneration and proliferation of embryonic and adult rat hippocampal neurons in culture. Exp Neurol 1999, 159(1):237-47.

4. Aksenova MV, Aksenov MY, Mactutus CF, Booze RM: Cell culture models of oxidative stress and injury in the central nervous system. Curr Neurovasc Res 2005, 2(1):73-89.

5. Aksenova MV, Aksenov MY, Markesbery WR, Butterfield DA: Aging in a dish: age-dependent changes of neuronal survival, protein oxidation, and creatine kinase BB expression in long-term hippocampal cell culture. J Neurosci Res 1999, 58(2):308-17.

6. Lesuisse C, Martin LJ: Long-term culture of mouse cortical neurons as a model for neuronal development, aging, and death. J Neurobiol 2002, 51(1):9-23

7. Brewer GJ, Lim A, Capps NG, Torricelli JR: Age-related calcium changes, oxyradical damage, caspase activation and nuclear condensation in response to glutamate and beta-amyloid. Exp Gerontol 2005, 40:426-437.

8. Kim MJ, Oh SJ, Park SH, Kang HJ, Won MH, Kang TC, Park JB, Kim J, Kim J, Lee JY: Neuronal loss in primary long-term cortical culture involves neurodegeneration-like cell death via calpain and $\mathrm{p} 35$ processing, but not developmental apoptosis or aging. Exp Mol Med 2007, 39(1):14-26.

9. Costantini C, Lorenzetto E, Cellini B, Buffelli M, Rossi F, Della-Bianca V: Astrocytes regulate the expression of insulin-like growth factor 1 receptor (IGF1-R) in primary cortical neurons during in vitro senescence. J Mol Neurosci 2010, 40(3):342-52.

10. Kaech S, Banker G: Culturing hippocampal neurons. Nat Protoc 2006, 1(5):2406-15.

11. Paek SH, Shin HY, Kim JW, Park SH, Son JH, Kim DG: Primary culture of central neurocytoma: a case report. J Korean Med Sci 2010, 25:798-803.

12. Palm K, Salin-Nordstrom T, Levesque MF, Neuman T: Fetal and adult human CNS stem cells have similar molecular characteristics and developmental potential. Molecular Brain Research 2000, 78:192-195.

13. Varghese K, Das M, Bhargava N, Stancescu M, Molnar P, Kinda MS, Hickman JJ: Regeneration and characterization of adult mouse hippocampal neurons in a defined in vitro system. J of Neuroscience Methods 2009, 177:51-59.
14. Eliasson C, Sahlgren C, Berthold CH, Stakeberg J, Celis JE, Betsholtz C, Eriksson JE, Pekny M: Intermediate filament protein partnership in astrocytes. J of BioChem 1999, 274(34):23996-24006.

15. Esteban JA: Living with the enemy: a physiological role for the $\beta$-amyloid peptide. Trends in Neuroscience 2004, 27:1-3.

16. Pearson HA, Pears C: Physiological roles for amyloid $\beta$ peptides. J Physiol 2006, 575:5-10.

17. Beach TG: Physiologic origins of age-related beta-amyloid deposition. Neurodegener Dis 2008, 5(3-4):143-5.

18. Lindner $A B$, Demarez $A$ : Protein aggregation as a paradigm of aging. Biochim Biophys Acta 2009, 1790(10):980-996.

19. Nakamura T, Lipton SA: Cell death: protein misfolding and neurodegenerative diseases. Apoptosis 2009, 14(4):455-468

20. Lesné S, Ali C, Gabriel C, Croci N, MacKenzie ET, Glabe CG, Plotkine M, Marchand-Verrechia C, Vivien D, Buisson A: NMDA receptor activation inhibits alpha-secretase and promotes neuronal amyloid-beta production. J Neurosci 2005, 25(41):9367-9377.

21. Kametani F: Epsilon-secretase: reduction of amyloid precursor protein epsilon-site cleavage in Alzheimer's disease. Curr Alzheimer Res 2008, , 5: 165-171

22. Kamenetz F, Tomita T, Hsieh H, Seabrook G, Borchelt D, Iwatsubo T, Sisodia S, Malinow R: APP processing and synaptic function. Neuron 2003, 37:925-937.

23. Puzzo D, Privitera L, Leznik E, Fà M, Staniszewski A, Palmeri A, Arancio O: Picomolar amyloid-beta positively modulates synaptic plasticity and memory in hippocampus. J Neurosci 2008, 28:14537-14545.

24. Rohan de Silva HA, Jen A, Wickenden C, Jen LS, Wilkinson SL, Patel AJ: Cellspecific expression of beta-amyloid precursor protein isoform mRNAs and proteins in neurons and astrocytes. Brain Res Mol Brain Res 1997, 47(1-2):147-156

25. Sarasa $M$, Pesini P: Natural non-transgenic animal models for research in Alzheimer's disease. Current Alzheimer Research 2009, 6:171-178.

26. Liu RT, Zou $L B, L u Q J$ J: Liquiritigenin inhibits $A \beta_{25-35}$-induced neurotoxicity and secretion of $A \beta_{1-40}$ in rat hippocampal neurons. Acta Pharmacologica Sinica 2009, 30:899-906

27. Hensley K, Hall N, Subramaniam R, Cole P, Harris M, Aksenov M Aksenova M, Gabbita SP, Wu JF, Carney JM, Lovell M, Markesbery WR, Butterfield DA: Brain regional correspondence between Alzheimer's disease histopathology and biomarkers of protein oxidation. $J$ Neurochem 1995, 65(5):2146-2156.

28. Selkoe DJ: Soluble oligomers of the amyloid beta-protein impair synaptic plasticity and behavior. Behav Brain Res 2008, 192:106-113.

29. Boyd-Kimball D, Sultana R, Mohmmad-Abdul H, Butterfield DA: Rodent Abeta(1-42) exhibits oxidative stress properties similar to those of human Abeta(1-42): Implications for proposed mechanisms of toxicity. J Alzheimers Dis 2005, 6(5):515-525.

30. Matrone C, Ciotti MT, Mercanti D, Marolda R, Calissano P: NGF and BDNF signaling control amyloidogenic route and $A \beta$ production in hippocampal neurons. PNAS 2008, 105(35):13139-13144.

31. Brewer GJ: Effects of acidosis on the distribution of processing of the beta-amyloid precursor protein in cultured hippocampal neurons. $\mathrm{Mol}$ Chem Neuropathol 1997, 31(2):171-86.

32. Misonou H, Trimmer JS: A primary culture system for biochemical analyses of neuronal proteins. J Neuroscience Methods 2005, 144:165-173.

33. Diez-Vives C, Gay M, Garcia-Matas S, Comellas F, Carrascal M, Abian J, Ortega-Aznar A, Cristofol R, Sanfeliu C: Proteomic study of neuron and astrocyte cultures from senescence-accelerated mouse SAMP8 reveals degenerative changes. J Neurochemistry 2009, 111:945-955.

34. Haass C, Schlossmacher MG, Hung AY, Vigo-Pelfrey C, Mellon A, Ostaszewski BL, Schenk D, Teplow DB, Selkoe DJ: Amyloid $\beta$-peptide is produced by cultured cells during normal metabolism. Nature 1992, 359:322-325

35. Butterfield DA, Yatin SM, Varadarajan S, Koppal T: Amyloid-beta-peptideassociated free radical oxidative stress, neurotoxicity, and Alzheimer's disease. Methods Enzymol 1999, 309:746-748.

36. Yatin SM, Varadarajan S, Link CD, Butterfield DA: In vitro and in vivo oxidative stress associated with Alzheimer's amyloid-beta peptide (1-42). Neurobiol Aging 1999, 20:338-342.

37. Moro ML, Collins MJ, Cappellini E: Alzheimer's disease and amyloid $\beta$ peptide deposition in the brain: a matter of 'aging'? Biochem Soc Trans 2010, 38:539-544. 
38. Wakabayashi M, Matsuzaki K: Formation of amyloids by Abeta-(1-42) on NGF-differentiated PC12 cells: roles of gangliosides and cholesterol. J Mol Biol 2007, 371:924-933.

39. Aksenov MY, Aksenova MV, Mactutus CF, Booze RM: HIV-1 proteinmediated amyloidogenesis in rat hippocampal cell culture. Neuroscience Letters 2010, 45:174-178.

40. Aksenov MY, Aksenova MV, Mactutus CF, Booze RM: Attenuated neurotoxicity of the transactivation-defective HIV-1 Tat protein in hippocampal cell cultures. Exp Neurol 2009, 219:586-590.

doi:10.1186/1471-2202-12-38

Cite this article as: Bertrand et al.: Endogenous amyloidogenesis in long-term rat hippocampal cell cultures. BMC Neuroscience 2011 12:38.

Submit your next manuscript to BioMed Central and take full advantage of:

- Convenient online submission

- Thorough peer review

- No space constraints or color figure charges

- Immediate publication on acceptance

- Inclusion in PubMed, CAS, Scopus and Google Scholar

- Research which is freely available for redistribution

Submit your manuscript at www.biomedcentral.com/submit 